Original paper

\title{
EFFECT OF ARTIFICIAL PROLONGED WINTERING ON EMERGENCE AND SURVIVAL OF OSMIA RUFA ADULTS
}

\author{
Karol Giejdasz* \\ Oskar Wasielewski \\ Institute of Zoology, Poznań University of Life Sciences \\ *corresponding author: kagiede@up.poznan.pl \\ Received: 28 March 2017; accepted: 11 May 2017
}

A bstract

This study discusses the longevity and emergence rate of 0 . rufa males and females after an extended wintering period in artificial conditions. Experimental activation of the wintering bees was carried out every fifteen days, starting at the end of March and finishing at the beginning of June (25 March, 9 April, 24 April, 9 May, 24 May, 8 June). In our study, the shortest emergence time (5 days) was observed in females that overwintered for at least 220 days and were activated at the beginning of May or later. Their mean emergence time in the last three terms was similar and ranged from 4.6 to 5.1 days. Prolonged wintering increased female emergence dynamics in May and June. Half of the emerged males in our study lived up to 28 days when activated during the first term, and up to 15 days when activated during the last one. In females, half of the bees lived up to 64 and 20 days, respectively.

Keywords: emergence, longevity, Osmia rufa, overwintering, survival

\section{INTRODUCTION}

Worldwide decline in pollinator abundance and diversity has been observed in the agricultural ecosystem in which bees are crucial for the successful production of seeds, fruits, and vegetables. Moreover, the performance of wild bees as pollinators has been declining steadily, particularly in intensive farming for which bees are often managed for crop pollination (Garibaldi et al. 2013; James \& Pitts-Singer 2008; Jauker 2012). Only a dozen of species have been commercialized for this purpose (Parker, Batra \& Tepedino 1987), and the most widely used pollinator is the honey bee (Corbet, Williams \& Osborne 1991). However, Apis mellifera the western honey bee is not the best pollinator for each and every crop.

Some solitary bees, whose activity period and forage plants are perfectly matched for particular crops, pollinate very effectively (Delaplane \& Mayer 2000). In recent years, improved rearing and management methods of bumblebees and a few species of solitary bees have been developed (Van den Eijnde et al. 1990; Bosch, Kemp, \& Peterson 2000; Gruber et al. 2011; Pitts-Singer \& Cane 2011). The most numerous species come from Osmia genus and are mostly managed for fruit tree pollination (Bosch \& Kemp 2000, 2002; Bosch, Kemp \& Trostle 2006; Gruber et al. 2011).

The red mason bee (Osmia rufa L.) is a univoltine and polylectic bee species, common in Central Europe, which accepts diverse pre-existing cavities for nesting (Tasei 1973; Westerich 1989; Ivanov 2006). The flying period of Osmia rufa lasts two months for females and about fifteen days for males (Tasei 1973). In Poland, their nesting activity starts at the end of March or in the beginning of April and ends in the second half of June (Wójtowski 1979). The life cycle of Osmia species can be divided into seven partially overlapping periods: nesting, development, prewintering, wintering, incubation, mating and prenesting (Bosch \& Kemp 2002). O. rufa is strictly univoltine solitary bee and a short-lived spring species wintering as adult bees in cocoons. For crops with short flowering periods, univoltine pollinators with relatively short nesting periods are desirable, if their nesting period matches the flowering period (Parker, Batra \& Tepedino, 1987). O. rufa and other species with a short 


\section{GIEJDRSZ Et HL. — O. rufa vitality after prolonged winter}

nesting period are poor pollinators of blooming plants beyond their natural flying period. Pollination management includes methods to synchronize bee emergence with the flowering of particular plant species.

In rearing practices, cocoons of $O$. rufa are stored in artificial condition at $4^{\circ} \mathrm{C}$ from the middle of January to the moment of plant bloom. Some days before the expected bloom, the mason bee cocoons are exposed to warm temperatures to induce the emergence of active adults. Artificial conditions allow for the controlling of the emergence time, the shortening or prolonging of the wintering period and thus the synchronization of bee emergence time with a particular crop's flowering period (Bosch \& Kemp, 2000, 2004; Sedivy \& Dorn, 2014). In Poland, the red mason bee has become commercially available and can be used from February until july. This bee species is recommended for the pollination of both field crops (e.g. rape) and greenhouse crops (e.g. strawberries) (Wilkaniec \& Radajewska, 1996; Teper \& Biliński, 2009). 0. rufa is also an efficient pollinator of vegetables (e.g. onion) and tolerates captivity in pollen isolation cages (Kaminski 2010). Therefore, this bee species is widely used by seed companies and plant growers.

During wintering, Osmia bees maintain metabolic activity by consuming only their fat body reserves, so prolonged winter brings about serious consequences. Wintering duration affects the fat body reserve and extended winters may cause high winter mortality or decreased longevity (Bosch \& Kemp, 2003; 2004). The time to emergence following incubation declines with increasing wintering duration and increasing wintering temperature (Bosch \& Kemp, 2004).

This study discusses the longevity and emergence rate of 0 . rufa males and females after the extended wintering period in artificial conditions. Its outcomes would be useful in improving the synchronization of bee emergence with the flowering time of various plants from March to June. Knowledge on the longevity of adult bees after a prolonged wintering period would allow for a better control of pollinator abundance during the entire flowering period, not only at its beginning. Moreover, our findings would improve the rearing and management practices of Osmia rufa as a crop pollinator.

\section{MATERIAL AND METHODS}

\section{Insects and experimental procedures}

Experiments were conducted in spring 2009 during the flying period of Osmia rufa. The experimental material consisted of bees reared in artificial nests made of reed stalks, as described by Wójtowski \& Wilkaniec (1978).

The nests occupied in spring 2008 were transferred to the laboratory at the beginning of January 2009. The reed tubes were sectioned longitudinally to remove cocoons which were then stored in a refrigerator until the beginning of the experiment. The artificial conditions of adult bees wintering were $4{ }^{\circ} \mathrm{C}$ and $40-50 \%$ humidity. To avoid the seasonal effect, all experimental cocooned bees were placed and stored in a constant laboratory temperature before the start of the experiment. An experiment with Osmia bees conducted by Sgolastra et al. (2010) clearly indicated that in the first phase of wintering period temperature have no effects on the survival and emergence rate of bees.

Experimental activation of the wintering bees was conducted every fifteen days, starting at the end of March and finishing at the beginning of June (25 March, 9 April, 24 April, 9 May, 24 May, 8 June). One hundred and twenty cocoons were transferred to Petri dishes and placed at $28^{\circ} \mathrm{C}$. The number of emerged $O$. rufaadults was checked every day until all live bees emerged from the cocoons. The sex of the emerged adults was determined according to morphological traits. The bees were settled into two acrylic glass cuboid cages $(25 \mathrm{~cm} \times 40 \mathrm{~cm} \times 25 \mathrm{~cm}$ ) and treated as one experimental group. One cage comprised of about 50 bees of both sexes. The emerged adult bees were kept in the laboratory at $22^{\circ} \mathrm{C}$ and 12:12 photoperiod. They were fed ad libitum sucrose solution (1:1) served in a Petri dish (5 cm diameter) with a perforated disc of honey bee comb foundation to prevent drowning. The cages were inspected every two days for 
the number of dead bees. Dead insects were removed and sucrose solution was changed at that time. This procedure was repeated until the last bee died. The groups of adult bees which emerged during each activation term included 45-59 males and 39-57 females each, so a total of 321 females and 308 males were used in the study.

\section{Data analysis}

Allstatisticalanalysesandgraphsweregenerated with Statistica software package (Statsoft, v.12). Emergence efficiency was evaluated with a chi-square test. The data on mean emergence time were analyzed by ANOVA with Tukey's post-hoc tests. Kruskal-Wallis one-way analysis of variance and multiple comparison tests showed the effect of prolonged wintering on bee longevity. Estimates of survival probability and survival curves were calculated according to the Kaplan-Meier method. The significant level was set at 0.05 .

\section{RESULTS}

\section{Emergence effectiveness}

The percent of emerged bees ranged from 73.3 to $94.2 \%$ (mean $87.4 \%$ ) at individual terms (Tab. 1). The greatest number of bees (113) emerged on 24 May and the lowest (88) on 9 May. On average, 105 bees left the prepared 120 cocoons, including 52 males and 53 females. The number of emerged bees did not differ from expectations in any group $(\chi 2=4.126, \mathrm{df}=5$, $p=0.531)$. This indicated that the emergence time did not reduce emergence effectiveness.

\section{Incubation time and emergence rate}

In the first (25 March) and second (9 April) terms, the first males appeared after three days, and first females after six days of incubating the cocoons at $28^{\circ} \mathrm{C}$. In the second terms, the emergence time was shorter, in the third (24 April) and fourth (9 May) terms the males emerged after two days, and in fifth (24 May) and sixth (8 June) after only one day (Fig. 1). In the beginning, females emerged slightly later than males (Fig. 1), but in May and June their emergence was more or less synchronized with just a short delay of one day in females. The incubation and emergence period from placing the cocoons in an oven until the emergence of the last bee was sixteen days for the first and second terms. In the next terms, the emergence period was considerably reduced and lasted only seven days for the last May and June terms.

The emergence period was the shortest in male bees and in the first two terms it took

Table 1

Number and percentage (in parentheses) of 0 . rufa adults emerged from cocoons incubated at $28^{\circ} \mathrm{C}$ at various terms

\begin{tabular}{lllll}
\hline & Term * & Males & Females & Both sexes \\
\hline 1 & 25 Mar. & $53(44.2)$ & $50(41.6)$ & $103(85.8)$ \\
2 & 09 Apr. & $59(49.2)$ & $52(43.3)$ & $111(92.5)$ \\
3 & 24 Apr. & $52(43.3)$ & $59(49.2)$ & $111(92.5)$ \\
4 & 09 May & $45(37.5)$ & $43(35.8)$ & $88(73.3)$ \\
5 & 24 May & $53(44.2)$ & $60(50.0)$ & $113(94.2)$ \\
6 & 08 June & $46(38.3)$ & $57(47.5)$ & $103(85.8)$ \\
\hline
\end{tabular}

* At each term 120 cocoons both sex were incubated 
1. $25 \mathrm{Mar}$

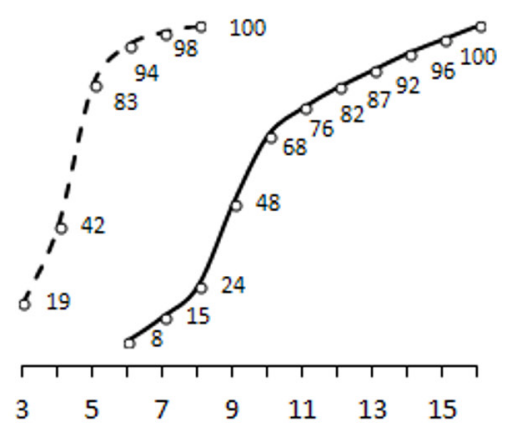

3. $24 \mathrm{Apr}$.

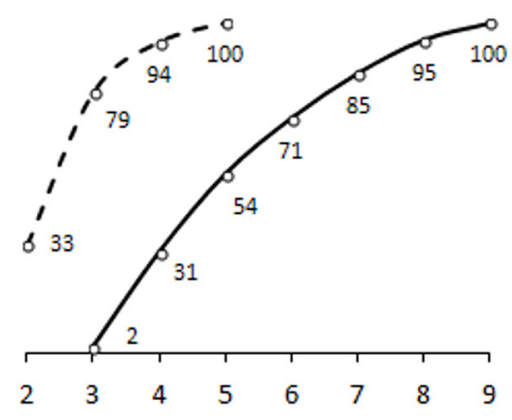

5. 24 May

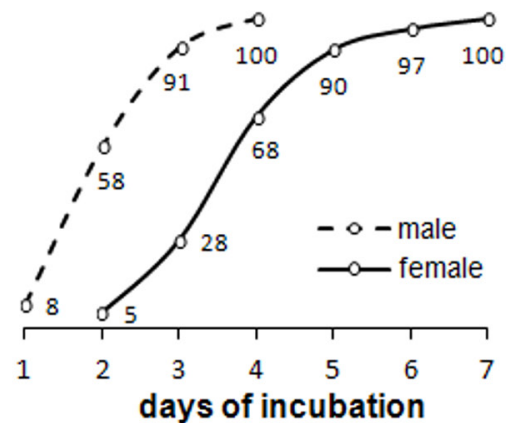

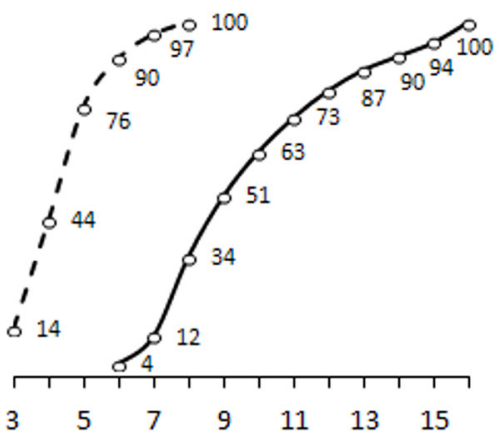
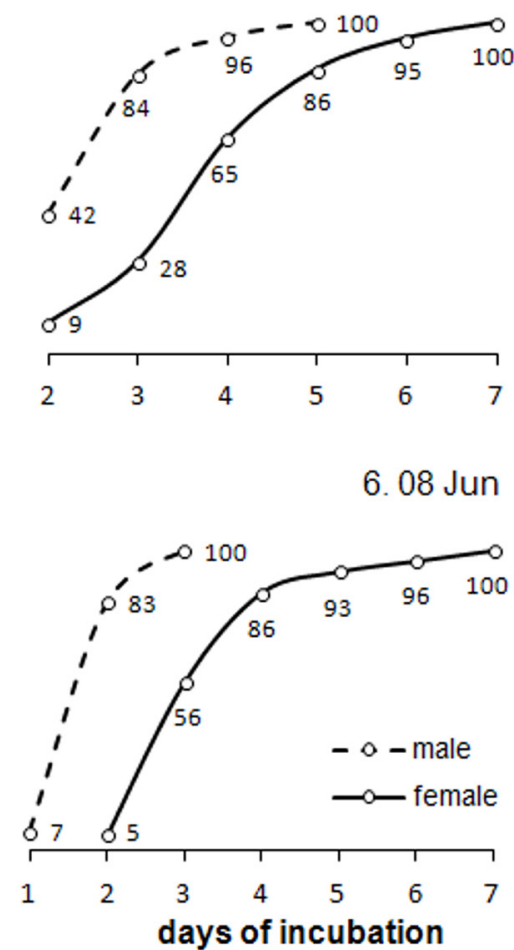

Fig. 1. Cumulative percentage of emerged male and female adults as a function of the number of days since the beginning of the incubation at $28^{\circ} \mathrm{C}$ at various terms $(\mathrm{N}=88-113$ depending on the term; see Table 1).

only eight days. In the next terms (3 to 6), the incubation and emergence time for male bees was shortened to three days. Similar emergence dynamics was observed in females, in which the initial emergence period of 16 days was reduced by over $50 \%$ (to seven days) in the final terms (Fig. 1).The curves of emerged bee frequency plotted against days of incubation were positively sloped and had a typical upward sloping shape for males at all terms. The emergence rate for males was very high for the first two or three days and then gradually
2. $09 \mathrm{Apr}$.

4. 09 May

6. 08 Jun

slowed down. In the first period of very dynamic emergence, the curve depicting male emergence rate quickly soared up to nearly $80 \%$. This was obviously dependent on the incubation time. However, the emergence rate of $80 \%$ for males was achieved quicker in the consecutive incubation periods. After five days of the incubation, $83 \%$ and $76 \%$ of male adults emerged in the first and second terms, respectively. After just three days of incubation, $78.8 \%, 84.4 \%$, and $90.6 \%$ of males emerged in third, fourth and fifth terms, respectively. In the last term, most of the males (82.6\%) emerged in two days.

The curves of emerged adult females in most of the terms were had sigmoid- shaped. Similarly as for males, emergence dynamics changed depending on the incubation time. In the first two terms, half of the females emerged after ten days of incubation. During the next incubations, the time to an emergence rate of $50 \%$ was shortened to five days (24 April), and reached three days for the last June term. A different emergence rate of $80 \%$ for males and $50 \%$ for females depended on biological traits, which was why direct comparisons between sexes were impossible. This difference in emergence dynamics was clearly visible in different terms, where $50 \%$ of emerged females often corresponded to $100 \%$ of emerged males in the same period.

\section{Mean emergence time}

One-way analysis of variance (ANOVA) revealed significant differences in mean emergence times of males and females. There were significant differences in days to emergence after incubation among various terms for males $(F=78.526 ; \quad d f=5.315 ; \quad p<0.001)$ and 
females ( $F=145.02 ; d f=5.304 ; \quad p<0.001)$, and the emergence time tended to decrease with artificially prolonged wintering period (Fig. 2). Moreover, males emerged faster than females, irrespective of the activation time. The longest emergence time for both sexes was observed in the first and second terms (25 Match, 9 April). The emergence time of both sexes decreased rapidly from the third term (24 April).

Post hoc analysis with Tukey's test revealed that adult males incubated in the last term emerged significantly more quickly than those in the first, second, third or fourth terms $(p<0.05)$. However, the emergence time of male bees incubated in the fifth term did not differ significantly from the third and fourth or last term. The post hoc test conducted separately for females revealed that female adults incubated in the fourth term or later had the most effectively reduced emergence time. Also, the emergence time of the females incubated during the third term differed significantly from those which emerged in the first and second terms or those from the fourth and later terms (Fig. 2).

Male and female survival

Kruskal-Wallis one-way analysis of variance demonstrated the effects of prolonged wintering on bee longevity. There was a statistically significant difference (K-W test; $\mathrm{H}(5$; $302)$ = 98.296; $p<0.001$ ) among the groups of males from various terms with respect to their survival probability estimates (Fig. 3). Median survival time (MST) in male adults incubated during terms 1 to 6 was 28, 24, 26, 24, 20 and 15 days, respectively (total median: 24 days).

The Kruskal-Wallis test and multiple comparison tests showed precise differences in survival times among particular groups of males. Significant differences were found in the MST between the first and fourth, fifth and sixth term $(p<0.001)$. The males activated in the second and third term had significantly longer MST than those activated in the fifth and sixth term $(p<0.001)$. The males activated in terms 1 to 3 lived considerably longer than those from the terms 5 and 6 (Fig. 3). The 15-day survival rate of males in sequenced terms (1-6) was $95.9 \%, 90.1 \%, 86.5 \%, 90.1 \%, 71.2 \%$, and $49.9 \%$, respectively. There was a significant difference in the survival time of female bees among groups from various terms (K-W test; $\mathrm{H}(5 ; 289)$ = 111.97; p<0.001), (Fig. 4). Median survival time (MST) in female adults incubated at terms 1 to

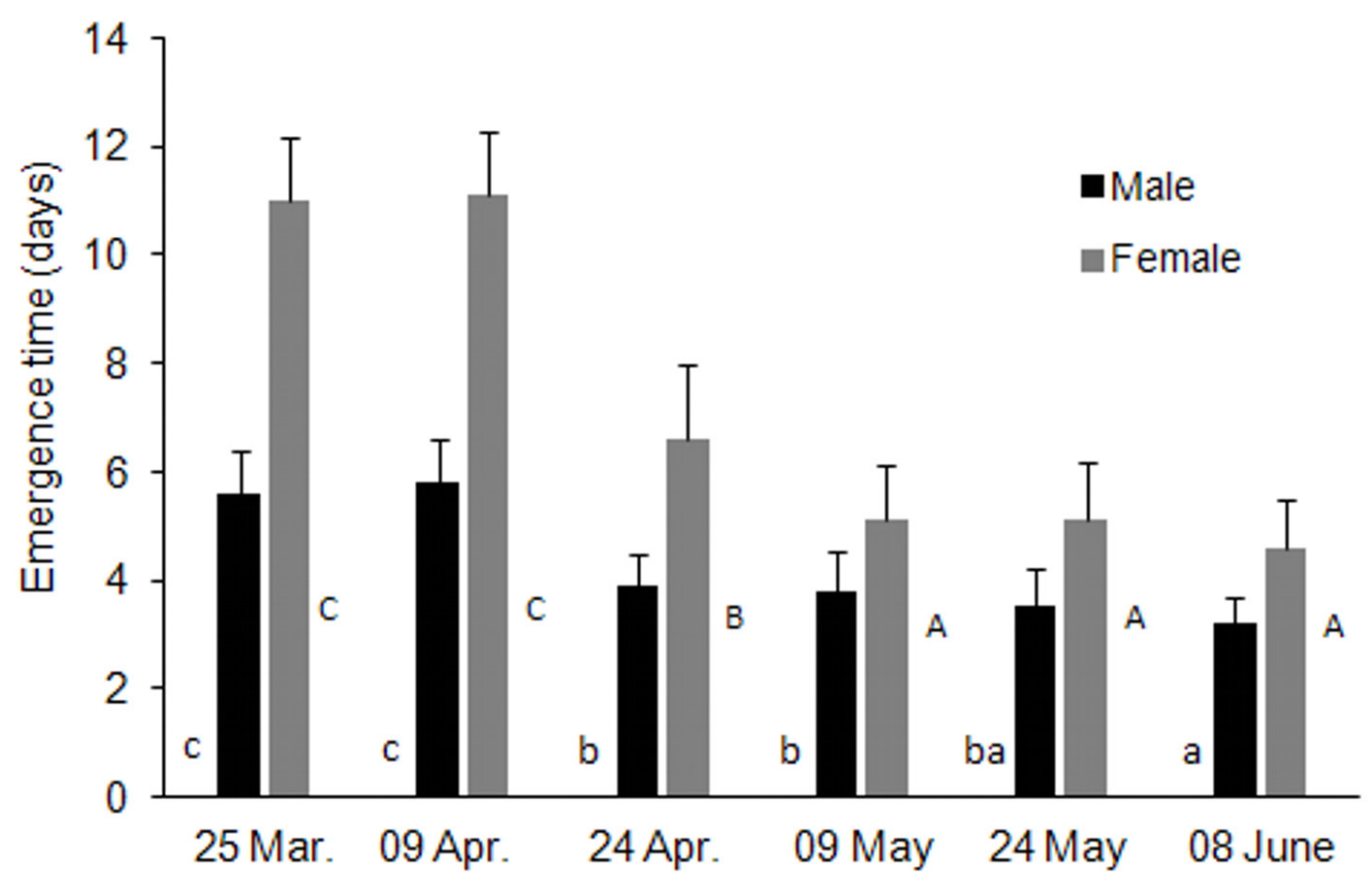

Fig. 2. Mean emergence time \pm SD depending on the activation time. Bars with different superscripts denote significant difference $(p<0.05$ ) based on One-Way ANOVA followed by Tukey's multiple comparison test 


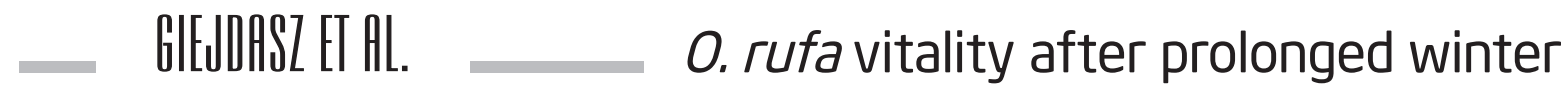

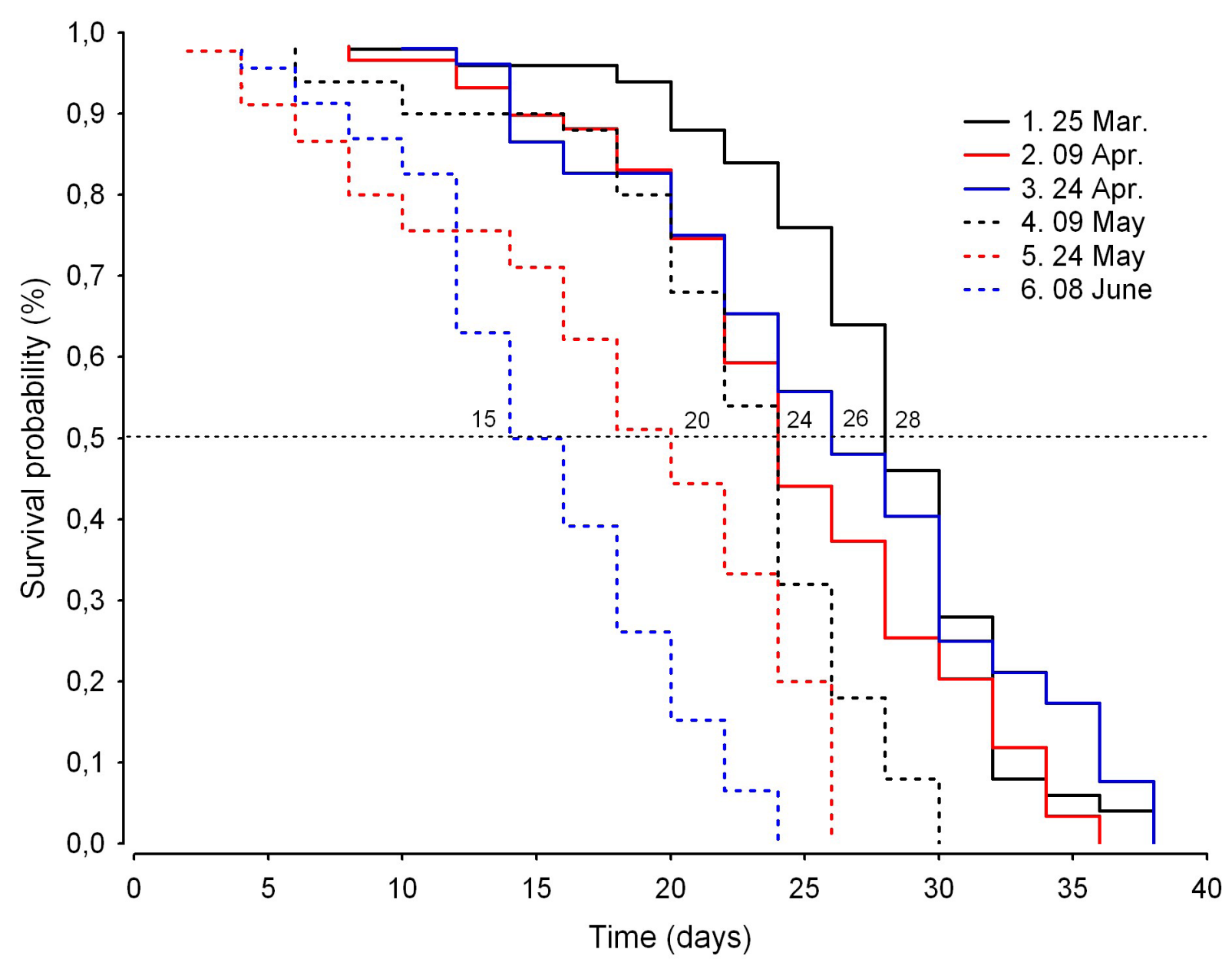

Fig. 3. Estimated longevity of O. rufa males activated at different terms (i.e. depending on wintering duration). Outcomes evaluated with Kaplan-Meier survival analysis ( $\mathrm{N}=88-113$ for different terms; see Table 1)

6 was $64,46,42,42,34$ and 20 days, respectively (total median: 36 days).

The Kruskal-Wallis test and multiple comparison tests showed precise differences in survival times among the groups of females. Significant differences were found in the MST between the first term group and MST for the other groups ( $p<0.001)$, except for the second term. However, a clear downward trend regarding survival ( $p$ $=0.059$ ) was also visible for the second term. Females activated during the sixth term had a significantly shorter MST than those from other terms $(2,3,4,5)(p<0.001)$. The 20 -day survival rate for females for consecutive terms (1-6) was $89.8 \%, 92.9 \%, 81.9 \%, 76.7 \%, 70.2 \%$, and $47.5 \%$, respectively.

\section{DISCUSSION}

Osmia rufa, an early spring species, turns into imago in September and overwinters in its nest in a cocoon made by a larva (Tasei, 1973; Wójtowski, 1979). Winter survival of the Osmia bee depends on such factors related to metabolic reserves as temperature during developmental stages, pre-wintering and wintering and their duration (Bosch \& Kemp, 2004; Kemp \& Bosch, 2005; Bosch, Sgolastra \& Kemp, 2010; Sgolastra et al., 2010; Radmacher \& Strohm, 2011). Prolonged wintering of univoltine species of Osmia genus causes increased mortality of wintering imago (Bosch \& Kemp, 2003). In our study, the number of adults emerging from the cocoons was similar irrespective of the time of their activation, so in this case prolonged wintering had no negative effects on bee survival.

The non-emerged cocoons usually contain dead developmental forms (рrepupa, pupa), imago that died before winter or parasitic larvae. The ratio of emerged bees to the number of cocoons retrieved from the nests determines the share of individuals that successfully completed 
late developmental stages and wintering. As the wintering form of 0 . rufa is commercially available and used for crop pollination, this ratio is commonly used to evaluate the number of pollinators introduced into a plantation (Krunic \& Stanisavljevic, 2006a).

In this experiment, the bees were stored from January at $4^{\circ} \mathrm{C}$ to inhibit emergence and prolong wintering. Higher temperature is not suitable for forced prolongation of diapause, and in controlled conditions, Osmia bees wintered for long periods at $7^{\circ} \mathrm{C}$ or higher temperature start to emerge after 150 days (from September) (Bosch \& Kemp, 2003). The bees for this experiment were kept in the field during their developmental period (April-mid-October) and stored at $4^{\circ} \mathrm{C}$ in a climate controlled container during their diapause period (mid-October-January). The temperature of $4^{\circ} \mathrm{C}$ is appropriate for storage, as it does not exceed the low temperature threshold for Osmia bee emergence.
The emergence rate may be adjusted with the incubation temperature when a lower temperature threshold is considered optimal for species emergence (White, Son \& Park, 2009).

Diapause in 0 . rufa is assumed to start in the beginning of October, so at the time of the first activation (25 March), the wintering period had already lasted for about 175 days (Wasielewski et al. 2011). This day was selected as in the central Europe climate the red mason bee can be seen in nature on the turn of March and April (Wójtowski 1979, Steffan-Dewenter \& Schiele 2004). Further activations were performed every fifteen days, and the wintering period was prolonged to the maximum of about 250 days.

For adult wintering species of Osmia genus, the emergence period is shortened as the over-wintering period is extended (Bosch \& Blas, 1994; Sgolastra et al., 2010). The time to emergence following incubation can be reduced by increasing

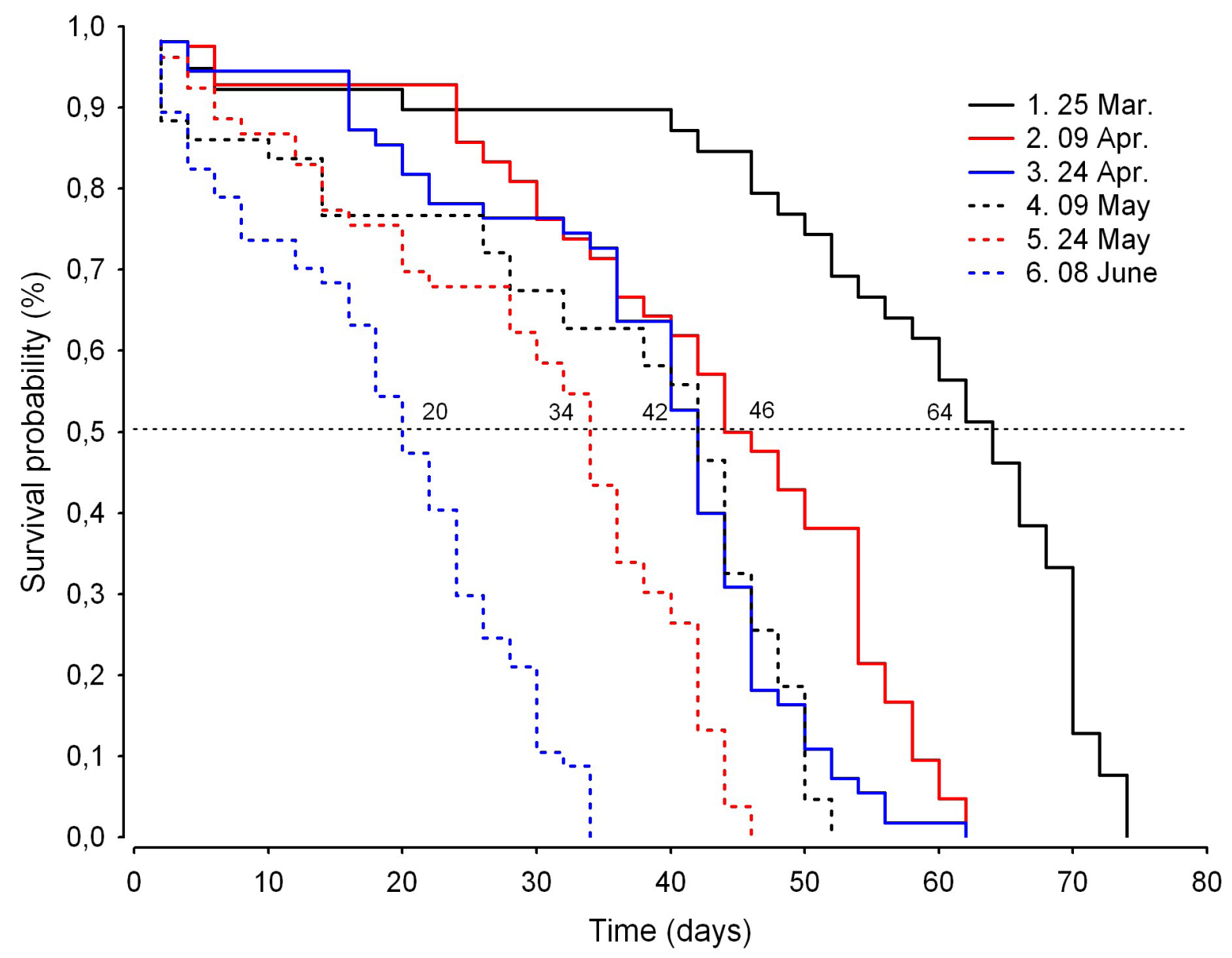

Fig. 4. Estimated longevity of 0 . rufa females activated at different terms (i.e. depending on wintering duration). Outcomes evaluated with Kaplan-Meier survival analysis ( $N=88-113$ for different terms; see Table 1) 
the wintering temperature when wintering lasts for no longer than 120 days (Bosch \& Kemp, 2003, 2004). In our experiment, all bees wintered in the same conditions, first natural and then controlled. Therefore, the factor that reduced the rate of adult bee activation and longevity was prolonged wintering.

Kemp \& Bosch (2005) determined the relationship between rearing temperatures and prepupa-adult development rates, as well as the emergence time and longevity in Osmia lignaria after wintering and incubation the following spring. The time to emerge following incubation (an indirect measure of diapause completion) was also affected by treatment in the pre-wintering period (Sgolastra et al., 2011). In general, temperature treatments that promoted rapid immature development and thus longer wintering periods resulted in earlier spring emergence patterns in bees. Warmer wintering periods also resulted in earlier emergence (Bosch, Kemp \& Peterson, 2000).

The mean female emergence time of Osmia cornuta for the longest wintering period tested (184 days) was as short as 4.6 days and female emergence period (time between the first and last female emergence) was only four days (Bosch \& Kemp, 2004). In our study, the shor test emergence time (5 days) was observed in females that overwintered for at least 220 days and were activated at the beginning of May or later. Their mean emergence time in the last three terms was similar and ranged from 4.6 to 5.1 days. Prolonged wintering increased female emergence dynamics in May and June.

The male emergence period and mean emergence time decreased along with wintering prolongation. Time, dynamics, and number of emerged adult males and females demonstrated the good condition of the insects. Prolonged wintering caused neither delay in adult emergence nor increased mortality due to exhaustion of reserves. The emergence time (days to emerge following incubation at $20^{\circ} \mathrm{C}$ ) was the shortest at intermediate pre-wintering durations, thus indicating that the emergence rate depended on both wintering time and bee condition associated with body weight and reduction of body fat reserves (Bosch, Sgolastra \& Kemp. 2010). Half of the males emerged in our study lived up to 28 days when activated in the first term, and up to 15 days when activated in the last one. In females, half of the bees lived up to 64 and 20 days, respectively. Prolonged wintering considerably shortened the longevity of the bees that wintered as imagos but this was only one factor affecting this parameter. Longevity clearly declined as wintering temperatures increased. At $4^{\circ} \mathrm{C}$, bees showed decreased longevity when wintered for longer than 150 days (Bosch \& Kemp, 2003).

Natural wintering period in Osmia rufa lasts for about 175 days but the bees are also ready for a later appearance (Krunić \& Stanisavljević, 2006b). Our findings seem to confirm this, as a significant decrease in longevity was observed in the females activated after 205 days of wintering (third term, 24 April) a), and in the males activated after 220 days of wintering (fourth term, 9 May).

In general, the entire course of ontogenesis affects univoltine species' condition and emergence times. Temperature adjustment during development and wintering may help to control the bee emergence time and minimize the loss of reserves from the fat body. Extended periods of high prewintering temperatures resulted in apparent fat body consumption in prewintering adults and reduction in springtime adult longevity (Bosch, Kemp \& Peterson, 2000). Individually, bees experiencing greater degree-day accumulations exhibited reduced post-winter longevity (Kemp \& Bosch, 2000; Kemp \& Bosch, 2005). Early developing individuals suffer greater weight loss and fat body depletion and have short post-winter longevity (Bosch, Sgolastra \& Kemp, 2010). The papers referenced above reported on adult bees' longevity without feeding, which describes the lifetime of bees that use up only their own energy reserves. In our study, half-field test was used to ensure the outcomes could be used in practice. We separately assessed females and males that are treated as useful pollinators. In closed spaces the roles of males might be similar to those of females that do not build nests in 
these conditions, do not gather large amounts of pollen and do not visit flowers (Fliszkiewicz, Giejdasz \& Wilkaniec, 2011; Ne'eman et al. 2006). The flowering period of many crops lasts for a few to several dozen days and individual flowers live for a few hours to a few days. The bees activated after prolonged wintering live long enough to be used for plant pollination. However, their density should probably be increased or they should be introduced more than once.

\section{REFERENCES}

Bosch, J., \& Blas, J. (1994). Effect of over-wintering and incubation temperatures on adult emergence in Osmia cornutaLatr. Apidologie, 25, 265-277.

Bosch, J., \& Kemp, W.P. (2000). Development and emergence of the orchard pollinator Osmia lignaria (Hymenoptera: Megachilidae). Environmental Entomology, 29, 8-13. DOl: 10.1603/0046-225X-29.1.8

Bosch, J., \& Kemp, W.P. (2002). Developing and establishing bee species as crop pollinators: the example of Osmia spp.(Hymenoptera: Megachilidae) and fruit trees. Biullety of Entomolgycal Research, 92, 3-16. DOl: 10.1079/BER2001139

Bosch, J., \& Kemp, W.P. (2003). Effect of wintering duration and temperature on survival and emergence time in males of the orchard pollinator Osmia lignaria (Hymenoptera: Megachilidae). Environmental Entomolgy, 32, 711-716. DOl: 10.1603/0046-225X32.4.711

Bosch, J., \& Kemp, W.P. (2004). Effect of pre-wintering and wintering temperature regimes on weight loss, survival, and emergence time in the mason bee Osmia cornuta (Hymenoptera: Megachilidae). Apido/ogie, 35,469-479. DOl: 10.1051/apido:2004035

Bosch, J., Kemp, W.P., \& Peterson, S.S. (2000). Management of Osmia lignaria (Hymenoptera: Megachilidae) populations for almond pollination: methods to advance bee emergence. Environmental Entomolgy, 29, 874-883. DOl: 10.1603/0046-225X-29.5.874
Bosch, J., Kemp, W. P., \& Trostle, G. E. (2006). Bee population returns and cherry yields in an orchard pollinated with Osmia lignaria (Hymenoptera: Megachilidae). Journal of Economic Entomology, 99(2), 408-413. DOl: http://dx.doi.org/10.1603/00220493-99.2.408

Bosch, J., Sgolastra, F., \& Kemp, W.P. (2010). Timing of eclosion affects diapause development, fat body consumption and longevity in Osmia lignaria, a univoltine, adult-wintering solitary bee. Journal of Insect Physiology, 56, 1949-1957. DOl: 10.1016/j.jinsphys.2010.08.017

Corbet, S. A., Williams, I. H., \& Osborne, J. L. (1991). Bees and the pollination of crops and wild flowers in the European Community. Bee World, 72, 47-59.

Delaplane, K. S., \& Mayer, D. F. (2000). Crop pollination by bees. Cambridge University Press.

Fliszkiewicz, M., Giejdasz, K., \& Wilkaniec, Z.A. (2011). The importance of male red mason bee (Osmia rufa L.) and male bufftailed bumblebee (Bombus terrestris L.) pollination in blackcurrant (Ribes nigrum L.). Journal of Horticultural Science and Biotechnolgy, 86, 457-460.

Garibaldi, L. A., Steffan-Dewenter, I., Winfree, R., Aizen, M. A., Bommarco, R., Cunningham, S. A., ... \& Bartomeus, I. (2013). Wild pollinators enhance fruit set of crops regardless of honey bee abundance. Science, 339(6127), 1608-1611. DOl: 10.1126/science. 1230200

Gruber, B., Eckel, K., Everaars, J., \& Dormann, C. F. (2011). On managing the red mason bee (Osmia bicornis) in apple orchards. Apidologie, 42, 564-576. DOl: 10.1007/s13592-011-0059-2

Ivanov, S. P. (2006). The nesting of Osmia rufa (L.)(Hymenoptera, Megachilidae) in the Crimea: Structure and composition of nests. Entomological Review, 86(5), 524-533. DOl: 10.1134/ S0013873806050046

James R., \& Pitts-Singer, T. L. (Eds.) (2008). Bee pollination in agricultural ecosystems. Oxford University 
Press.

Jauker, F., Bondarenko, B., Becker, H. C., \& SteffanDewenter, I. (2012). Pollination efficiency of wild bees and hoverflies provided to oilseed rape. Agricultural and Forest Entomology, 14(1), 81-87. DOl: 10.1111/j.1461-9563.2011.00541.x

Kaminski P. (2010). Gametoclonal and Somaclonal Variation among Head Cabbage Androgenic Lines of R1 and R2 Generations Obtained from Jaguar F1 Hybrid. Journal Agricultural Science, 2(2), 119.

Kemp, W. P., \& Bosch, J. (2000). Development and emergence of the alfalfa pollinator Megachile rotundata (Hymenoptera: Megachilidae). Annals of the Entomological Society of America, 93(4), 904-911.

Kemp, W. P., \& Bosch, J. (2005). Effect of temperature on Osmia lignaria (Hymenoptera: Megachilidae) prepupa-adult development, survival, and emergence. Journal of Economic Entomology, 98(6), 1917-1923. DOl: 10.1093/jee/98.6.1917

Krunic, M., \& Stanisavljevic, L. (2006a). Augmentation of managed populations of Osmia cornuta and O. rufa (Hymenoptera: Megachilidae) in Southeastern Europe. European Journal of Entomology, 103(3), 695-697.

Krunić, M. D., \& Stanisavljević, L. Ž. (2006b). Supercooling points and diapause termination in overwintering adults of orchard bees Osmia cornuta and 0 . rufa (Hymenoptera: Megachilidae). Bulletin of Entomological Research, 96, 323-326. D0l: https://doi. org/ 10.1079/ BER2006423

Ne'eman, G., Shavit, O., Shaltiel, L., \& Shmida, A. (2006). Foraging by male and female solitary bees with implications for pollination. Journal of Insect Behavior, 19(3), 383. DOl: 10.1007/s10905-006-90307

Parker, F.D., Batra, S.W.T., \& Tepedino, V.J. (1987). New pollinators for our crops. Agricultural Zoologica Reviews, 2, 279-304.

Pitts-Singer, T.L., \& Cane,J.H. (2011). The Alfalfa Leaf- cutting Bee, Megachile rotundata. The World's Most Intensively Managed Solitary Bee. Annual Review of Entomolgy, 56, 221-237. doi:10.1146/annurevento-120709-144836

Radmacher, S., \& Strohm, E. (2011). Effects of constant and fluctuating temperatures on the development of the solitary bee Osmia bicornis (Hymenoptera: Megachilidae). Apidologie, 42,711-720. DOl:10.1007/s13592-011-0078-9

Sedivy, C., \& Dorn, S. (2014). Towards a sustainable management of bees of the subgenus Osmia (Megachilidae; Osmia) as fruit tree pollinators. Apidologie, 45, 88-105. DOl: 10.1007/s13592-013-02318

Sgolastra, F." Bosch, J., Molowny-Horas, R., Maini, S., \& Kemp, W.P. (2010). Effect of temperature regime on diapause intensity in an adult-wintering Hymenopteran with obligate diapause. Journal of Insect Physiology, 56, 185-194. DOI: 10.1016/j.jinsphys.2009.10.001

Sgolastra, F., Kemp, W.P., Buckner, J.S., Pitts-Singer, T.L., Maini, S., \& Bosch, J. (2011). The long summer: pre-wintering temperatures affect metabolic expenditure and winter survival in a solitary bee. Journal of Insect Physiology, 57, 1651-1659. DOl: 10.1016/j.jinsphys.2011.08.017

Steffan-Dewenter, I. N., \& Schiele, S. (2004). Nestsite fidelity, body weight and population size of the red mason bee, Osmia rufa (Hymenoptera: Megachilidae), evaluated by mark-recapture experiments. Entomologia Generalis, 272), 123-131.

Tasei J. N. (1973). Le comportement de nidification chez. Osmia IOsmia) cornuta. Latr. et Osmia rufa L (Hymenoptera: Megachilidae). Apidologie 4, 195-315.

Teper, D., \& Bilinski M. (2009). Red mason bee (Osmia rufa L.) as a pollinator of rape plantations. Journal of Apicultural Science, 53, 115-120.

Van den Eijnde, J., De Ruijter, A., \& Van der Steen, J. (1990). Method for rearing Bombus terrestris continuously and the production of bumblebee colonies 
for pollination purposes. Acta Horticultural, 288, 154-158.

Wasielewski, O., Giejdasz, K., Wojciechowicz, T., \& Skrzypski, M. (2011). Ovary growth and protein levels in ovary and fat body during adult-wintering period in the red mason bee, Osmia rufa L. Apidologie, 42, 749-758. DOl: 10.1007/s13592-011-0084-y

Westrich, P. (1989). Die Wildbienen Baden Württembergs. Stuttgart, Eugen Ulmer Press.

Wilkaniec, Z., \& Radajewska, B. (1996). Solitary bee Osmia rufaL.(Apoidea, Megachilidae) as pollinator of strawberry cultivated in an unheated plastic tunnel. In Proceedings of III International Strawberry Symposium (p. 489-494).

White, J., Son, Y., \& Park, Y-P. (2009). Temperature-Dependent Emergence of Osmia cornifrons (Hymenoptera: Megachilidae) Adults. Journal of Economic Entomology,102, 2026-2032. DOl: 10.1603/029.102.0602

Wójtowski, F., \& Wilkaniec, Z. (1978). Rearing and utilization of solitary bees settled in nest traps (in Polish). Instr. Wdroż. AR Poznań, 1-10.

Wójtowski, F. (1979). Spostrzeżenia nad biologią i możliwościami użytkowania pszczoły murarki - Osmia rufa L. (Apoidea, Megachilidae) (in Polish). Roczniki AR w Poznaniu, 177, 203-208. 